\title{
Obesity Paradox in Short-Term Clinical Outcomes After Percutaneous Coronary Interventions
}

\author{
Mohammad Khalilur Rahman Siddiqui ${ }^{1}$, Pradip Kumar Karmakar ${ }^{2}$, Nur Alam ${ }^{3}$, Md. Mizanur Rahman ${ }^{4}$, Pranob \\ Karmaker ${ }^{5}$, Mohammad Morshedul Ahsan ${ }^{6}$, Anup Kumar Howlader ${ }^{7}$, Fahdia Afroz ${ }^{8}$, Chowdhury Md. Kudrat-E- \\ Khuda $^{9}$, Abhijit Roy ${ }^{10}$
}

\begin{abstract}
Background: The "obesity paradox", a counterintuitive decrease in morbidity and mortality with increasing body mass index (BMI), has been shown in patients when acute cardiovascular decompensation occurs. However, whether this phenomenon exists in patients undergoing percutaneous coronary intervention (PCI) is not well known. The existence of obesity paradox and its impact on short-term clinical outcomes after $\mathrm{PCI}$ have not been thoroughly investigated, especially in Bangladesh.

Methods: This cross-sectional observational study was conducted at National Institute of Cardiovascular Diseases, Dhaka, in 100 patients who underwent $\mathrm{PCI}$. They were divided in two groups on the basis of BMI of Asian ethnicity: Group I (BMI $<23 \mathrm{~kg} / \mathrm{m}^{2}$ ) and Group II $\left(B M I \geq 23.0 \mathrm{~kg} / \mathrm{m}^{2}\right)$. Short-term in-hospital outcomes after $\mathrm{PCl}$ were observed and recorded.
\end{abstract}

Results: Acute left ventricular failure (LVF) was found to be statistically significant between groups $(p<0.01)$ being higher in Group-I. The difference of mean duration of hospital stay (LOS) after PCI was higher in the same group which was statistically significant $(p<0.01)$. Diabetes mellitus and dyslipidemia were found to be the independent predictors for developing adverse inhospital outcome (OR=1.68 and 1.46; $95 \% \mathrm{Cl}=1.25-2.24$ and $1.16-1.83 ; p=0.018$ and 0.040 , respectively). BMI was inversely associated with in-hospital outcomes after $\mathrm{PCl}(\mathrm{OR}=0.95 ; 95 \% \mathrm{Cl}=0.91-0.98 ; \mathrm{p}=0.007)$.

Conclusion: The results of the study uphold the phenomenon of the "obesity paradox" following PCI. The underweight and normal weight people are at greater risk to experience short-term in-hospital adverse clinical outcomes than overweight and obese people after $\mathrm{PCl}$.

Key words: obesity paradox, reverse epidemiology, percutaneous coronary interventions

(Bangladesh Heart Journal 2021; 36(1): 1-8)

Introduction:

The relationship of obesity with cardiovascular disease and mortality in general population was found to be existing in a good number of epidemiological studies. ${ }^{1-4}$ At present, the conventional way to categorize obesity is

1. Assistant Professor, Cardiology, Cumilla Medical College, Cumilla.

2. Associate Professor, Cardiology, National Institute of Cardiovascular Diseases, Dhaka.

3. Associate Professor, Cardiology, National Institute of Cardiovascular Diseases, Dhaka.

4. Professor, Cardiology, Cumilla Medical College, Cumilla

5. Senior Consultant, Cardiology, 250 Bedded General Hospital, Tangail.

6. Assistant Professor, Cardiology, Shaheed Ziaur Rahman Medical College, Bogura.

7. Junior Consultant, Cardiology, National Institute of Cardiovascular Diseases, Dhaka

8. Assistant Professor, Cardiology, National Institute of Cardiovascular Diseases, Dhaka.

9. Assistant Professor, Cardiology, National Institute of Cardiovascular Diseases, Dhaka.

10. Junior Consultant, Cardiology, National Institute of Cardiovascular Diseases, Dhaka

Address of Correspondence: Dr. Mohammad Khalilur Rahman Siddiqui, Assistant Professor, Department of Cardiology, Cumilla Medical College, Cumilla, Bangladesh. Email: drmkrs@gmail.com

DOI: https://doi.org/10.3329/bhj.v36i1.55511

Copyright $\odot 2017$ Bangladesh Cardiac Society. Published by Bangladesh Cardiac Society. This is an Open Access articles published under the Creative Commons Attribution-NonCommercial 4.0 International License (CC BY-NC). This license permits use, distribution and reproduction in any medium, provided the original work is properly cited and is not used for commercial purposes. 
by the body mass index (BMI). ${ }^{5} \mathrm{BMI}$, also known as the Quetelet index [i.e., ratio of weight $(\mathrm{kg})$ to height squared $\left(\mathrm{m}^{2}\right)$ ] and other adjusted measures of weight (such as for height) are the commonly used parameters to quantify changes in body mass adjusted for height, and the association between body mass and outcome. ${ }^{4,6}$ In some studies of normal adults, a $\mathrm{J}$ or $\mathrm{U}$ curve effect has been observed in which those individuals with a low BMI also demonstrated an increased mortality, although not as high as obese individuals. ${ }^{1,2,7}$ The term "obesity paradox" refers to the observations that, although obesity is a major risk factor in the development of cardiovascular and peripheral vascular disease, when acute cardiovascular decompensation occurs, for example, in myocardial infarction or congestive heart failure, obese patients may have a survival benefit. ${ }^{8}$

This counterintuitive discovery in the relationship between obesity and various clinical issues, explained by the existence of obesity paradox, is denoted as "reverse epidemiology" by some authors. The concept of reverse epidemiology appears at first to be confusing, especially because hypertension, obesity, and high levels of serum cholesterol, creatinine, and homocysteine are established risk factors for ischemic heart disease in the general population. ${ }^{9}$ All these traditional risk factors of a poor clinical outcome and mortality in the general population are also found to be related to various outcomes but in an opposite direction. ${ }^{10}$ The paradox becomes even more paramount when it is recognized that it is not a question of the existence or lack of an association between these risk factors and the clinical outcomes, but often the complete reversal and indeed the opposite direction of this relationship. ${ }^{9}$

Despite marked disparity in values, there seems to be a rising prevalence of coronary artery disease (CAD) in Bangladesh. ${ }^{11}$ Globally, $30 \%$ of all deaths can be attributed to cardiovascular disease, of which more than half are caused by CAD. ${ }^{12}$ With the combination of sophisticated equipment, experienced operators, and modern drug therapy, coronary angioplasty has evolved into an effective nonsurgical modality for treating patients with CAD. ${ }^{13}$ The number of PCls is expected to grow modestly ( $1 \%$ to $5 \%)$ over the next decade as a result of the aging population and an increased frequency of diabetes and obesity. ${ }^{14}$

Institute for Health Metrics and Evaluation at University of Washington reported $17 \%$ of adults of Bangladesh as overweight or obese..$^{12}$ The complex interplay between abdominal obesity and insulin resistance appears to be a prime candidate in explaining this excess cardiovascular risk of South Asian people. The recognition and adoption of ethnic-specific BMI cutoffs represent a major step forward in refining risk stratification in different ethnic groups, including South Asians. ${ }^{15,16}$ There are limited data, however, on the relationship of BMI as a prognostic risk factor for outcomes following revascularization procedures such as $\mathrm{PCl} .{ }^{17}$

\section{Methods}

In the Department of Cardiology, National Institute of Cardiovascular Diseases and Hospital, Dhaka, this cross-sectional observational study was conducted, and by purposive sampling technique total 100 patients who underwent $\mathrm{PCl}$ were selected. Study subjects were divided on the basis of their BMI in accordance with Asian ethnicity into two equal groups each containing 50 patients: Group I (BMI $\left.<23 \mathrm{~kg} / \mathrm{m}^{2}\right)$ and Group II (BMI $\geq 23.0$ $\mathrm{kg} / \mathrm{m}^{2}{ }^{2}$ ). Patients with chronic kidney diseases, chronic liver disease, chronic obstructive pulmonary disease, valvular heart disease, congenital heart disease, cardiomyopathy, previous history of revascularization were excluded from the study. Patients undergoing primary $\mathrm{PCl}$, transradial interventions were not included, also. No ethical violation was made in conducting the study.

After having matched the inclusion and exclusion criteria the patients were selected for this study. Weight and height were measured and recorded in all participants by a standard medical scale and stadiometer, respectively. Self-reported weight or height was not accepted. BMI was calculated, categorized and recorded accordingly. $\mathrm{PCl}$ was done by transfemoral approach. Following $\mathrm{PCl}$ patients were monitored at Coronary Care Unit for at least 24 hours. Post-PCl development of in-hospital left ventricular failure along with common adverse outcomes were observed and recorded, i.e., bleeding, stroke, vascular access site complications, post- $\mathrm{PCl}$ ischemic chest pain, myocardial infarction with $\mathrm{PCl}$, significant arrhythmia, acute stent thrombosis, repeat revascularization, contrast induced nephropathy, cardiogenic shock, cardiovascular death.

To adjust for the potential confounders in predicting the association between BMI and in-hospital outcomes, logistic regression analysis was performed. Univariate logistic regression analysis was performed to specify the odds ratio $(\mathrm{OR})$ for overall adverse in-hospital outcomes. Multivariate logistic regression analysis was then performed by using SPSS 23.0 to investigate independent predictors for adverse in-hospital outcomes. Variables yielding $p$ values $\leq 0.05$ in univariate analysis were selected for multivariate model. Statistical significance was assumed if $p \leq 0.05$ throughout the study. 


\section{Results:}

Out of 100 studied patients $84 \%$ were male and $16 \%$ were female. Male to female ratio was 4.5:1. No significant association $(p>0.05)$ was found between the groups in terms of sex distribution. The mean age of the patients was $51.1 \pm 9.57$ years and the mean age difference between two groups was not statistically significant $(p>0.05)$. In both of the groups the highest percentages of patients were in the age range of $41-50$ years (Table-I).
Table II shows that among the different risk factors dyslipidemia, hypertension and diabetes mellitus were significantly more in group II (<0.05). The other risk factors i.e., smoking and family history of CAD were not significantly different between the groups $(p>0.05)$.

The difference of means of height was insignificant $(p>0.05)$ across the groups. But that of weight was found to be significant $(p=0.001)$. BMI was significantly $(p=0.001)$ higher in group II than group I. The

Table - I

Comparison of the study groups by their demographic characteristics $(N=100)$.

\begin{tabular}{|c|c|c|c|c|c|c|c|}
\hline \multirow[t]{3}{*}{ Age in years } & \multicolumn{4}{|c|}{$\mathrm{BMI}$} & \multicolumn{2}{|c|}{ Total $(N=100)$} & \multirow[t]{3}{*}{$p$-value } \\
\hline & \multicolumn{2}{|c|}{ Group I $(n=50)$} & \multicolumn{2}{|c|}{ Group II $(n=50)$} & & & \\
\hline & Number & $\%$ & Number & $\%$ & Number & $\%$ & \\
\hline$\leq 40$ & 4 & 8.0 & 5 & 10.0 & 9 & 9.0 & ${ }^{\mathrm{a}} 0.11^{\mathrm{NS}}$ \\
\hline $41-50$ & 23 & 46.0 & 25 & 50.0 & 48 & 48.0 & \\
\hline $51-60$ & 17 & 34.0 & 14 & 28.0 & 31 & 31.0 & \\
\hline$>60$ & 6 & 12.0 & 6 & 12.0 & 12 & 12.0 & \\
\hline Mean \pm SD & $51.2 \pm 11.4$ & $50.9 \pm 9.1$ & $51.1 \pm 9.57$ & ${ }^{\mathrm{b}} 0.91^{\mathrm{NS}}$ & & & \\
\hline \multicolumn{8}{|l|}{ Sex } \\
\hline Male & 43 & 86.0 & 41 & 82.0 & 84 & 84.0 & ${ }^{\mathrm{a}} 0.92^{\mathrm{NS}}$ \\
\hline Female & 7 & 14.0 & 9 & 18.0 & 16 & 16.0 & \\
\hline
\end{tabular}

Group I = Patients with BMI $<23 \mathrm{~kg} / \mathrm{m}^{2}$

Group II = Patients with BMI $\geq 23 \mathrm{~kg} / \mathrm{m}^{2}$

NS $=$ Not Significant $(p>0.05)$

${ }^{a} p$-value reached from chi-squared $\left(\chi^{2}\right)$ test and Fisher exact test

${ }^{\mathrm{b}} p$-value reached from unpaired t-test

Table-II

Comparison of the study groups according to their risk factors $(N=100)$

\begin{tabular}{|c|c|c|c|c|c|c|c|}
\hline \multirow[t]{3}{*}{ Risk factors } & \multicolumn{4}{|c|}{$\mathrm{BMI}$} & \multicolumn{2}{|c|}{ Total $(\mathrm{N}=100)$} & \multirow[t]{3}{*}{$p$-value } \\
\hline & \multicolumn{2}{|c|}{ Group I $(n=50)$} & \multicolumn{2}{|c|}{ Group II $(n=50)$} & & & \\
\hline & Number & $\%$ & Number & $\%$ & Number & $\%$ & \\
\hline Smoking & 20 & 40.0 & 24 & 48.0 & 44 & 44.0 & $0.587^{\mathrm{NS}}$ \\
\hline DM & 9 & 18.0 & 21 & 42.0 & 30 & 30.0 & $0.038^{S}$ \\
\hline Hypertension & 11 & 22.0 & 23 & 46.0 & 34 & 34.0 & $0.048^{s}$ \\
\hline Dyslipidemia & 7 & 14.0 & 20 & 40.0 & 27 & 27.0 & $0.022^{s}$ \\
\hline Family history of CAD & 14 & 28.0 & 14 & 28.0 & 28 & 28.0 & $0.931^{\mathrm{NS}}$ \\
\hline
\end{tabular}

Group I = Patients with BMI $<23 \mathrm{~kg} / \mathrm{m}^{2}$

Group II = Patients with BMI $\geq 23 \mathrm{~kg} / \mathrm{m}^{2}$

$\mathrm{DM}=$ Diabetes Mellitus

CAD = Coronary Artery Disease

$\mathrm{S}=$ Significant $(p<0.05)$

NS $=$ Not Significant $(p>0.05)$

$p$-value reached from chi-squared $\left(\chi^{2}\right)$ test 
breakdown of total patient would be 81 in Group I and 19 in Group II with statistically significant difference ( $p$ $=0.001$ ) of mean BMI across the group had their conventional non-Asian BMI cut-off value been used (Table III).

The difference of means of height between the two sex groups was significant $(p=0.001)$. The difference of means of weight across these groups was also significant $(p<0.01)$. BMl was higher in female patients than in male but the difference between them was not statistically significant in any group $(p>0.05)$ (Table IV).

Table $V$ compares the distribution of clinical presentations between the groups. The percentage of STEMI was the highest in both groups. No statistically significant difference was noted between the two groups $(p>0.05)$.
Table VI shows that the baseline LV function measured by echocardiography between the two study groups was not statistically significant $(p>0.05)$. The difference of mean LVEF was also insignificant statistically $(p>0.05)$ between the groups. Post-PCl echocardiography to assess LV function was not done routinely.

Table VII shows that the difference of mean length of hospital stay was statistically significant $(p<0.01)$. The difference of frequency distributions of the patients in this two study groups according to hospital stay time was also significant $(p<0.05)$.

The adverse in-hospital outcomes were significantly $(p<0.01)$ higher in Group I than Group II. Among all adverse in-hospital outcomes, only acute LVF was found to be statistically significant between the two study groups $(p<0.01)$ (Table VIII).

Table - III

Comparison of the study groups by their height, weight and BMI $(N=100)$.

\begin{tabular}{|c|c|c|c|c|}
\hline \multirow[t]{3}{*}{ Parameters } & \multicolumn{2}{|c|}{$\mathrm{BMI}$} & \multirow[t]{2}{*}{ Total( $\mathrm{N}=100)$} & \multirow[t]{3}{*}{$p$-value } \\
\hline & Group I $(n=50)$ & Group II $(n=50)$ & & \\
\hline & Mean $\pm S D$ & Mean $\pm S D$ & Mean \pm SD & \\
\hline Height(in meter) & $1.61 \pm 0.07$ & $1.63 \pm 0.06$ & $1.62 \pm 0.06$ & $0.26^{\mathrm{NS}}$ \\
\hline Weight(in kilogram) & $55.5 \pm 5.5$ & $65.7 \pm 5.9$ & $63.4 \pm 7.2$ & $0.001^{\mathrm{s}}$ \\
\hline \multirow[t]{2}{*}{ BMI cutoff value $23 \mathrm{~kg} / \mathrm{m}^{2}$} & $21.3 \pm 1.4$ & $24.7 \pm 1.4$ & $23.9 \pm 1.9$ & $0.001^{\mathrm{s}}$ \\
\hline & ${ }^{*}$ Group I (n=81) & ${ }^{*}$ Group II $(n=19)$ & & \\
\hline BMI cutoff value $25 \mathrm{~kg} / \mathrm{m}^{2}$ & $23.3 \pm 1.5$ & $26.7 \pm 1.3$ & $23.9 \pm 1.9$ & $0.001^{\mathrm{s}}$ \\
\hline
\end{tabular}

Group I = Patients with BMI $<23 \mathrm{~kg} / \mathrm{m}^{2}$

Group II = Patients with $\mathrm{BMI} \geq 23 \mathrm{~kg} / \mathrm{m}^{2}$

${ }^{*}=\mathrm{Had}$ non-Asian BMI category been used in this study

$\mathrm{S}=$ Significant $(p<0.05)$

NS $=$ Not Significant $(p>0.05)$

$p$-value reached from unpaired t-test

Table - IV

Comparison of height, weight and BMI within each study groups by sex of the patients $(N=100)$.

\begin{tabular}{|c|c|c|c|c|c|c|}
\hline \multirow[t]{2}{*}{ Study group } & \multicolumn{2}{|c|}{ Male $(n=84)$} & \multicolumn{2}{|c|}{ Female $(n=16)$} & \multirow{2}{*}{$\begin{array}{c}\text { Mean } \pm \text { SD } \\
(N=100)\end{array}$} & \multirow[t]{2}{*}{$p$-value } \\
\hline & Number & Mean \pm SD & Number & Mean \pm SD & & \\
\hline Height in meter & 84 & $1.64 \pm 0.04$ & 16 & $1.51 \pm 0.06$ & $1.62 \pm 0.06$ & $0.001^{\mathrm{s}}$ \\
\hline Weight in kilogram & 84 & $64.5 \pm 6.3$ & 16 & $56.4 \pm 8.6$ & $63.4 \pm 7.2$ & $0.006^{\mathrm{S}}$ \\
\hline Group I $(n=50)$ & 43 & $21.2 \pm 1.4$ & 7 & $21.9 \pm 0.8$ & & $0.436^{N S}$ \\
\hline \multirow[t]{2}{*}{ Group II $(n=50)$} & 41 & $24.6 \pm 1.3$ & 9 & $25.3 \pm 1.9$ & & $0.169^{N S}$ \\
\hline & 84 & $23.9 \pm 1.9$ & 16 & $24.5 \pm 2.3$ & $23.9 \pm 1.9$ & $0.294^{\mathrm{NS}}$ \\
\hline
\end{tabular}

Group I = Patients with BMI $<23 \mathrm{~kg} / \mathrm{m}^{2}$, Group II = Patients with BMI $\geq 23 \mathrm{~kg} / \mathrm{m}^{2}$.

$S=$ Significant $(p<0.05)$

NS $=$ Not Significant $(p>0.05)$

$p$-value reached from unpaired t-test 
Smoking and family history of CAD were not included in multivariate model as univariate analysis yielded them as statistically insignificant in the current study $(\mathrm{OR}=1.29$ and $1.10 ; 95 \% \mathrm{Cl}=0.82-1.78$ and $0.46-$ $1.75 ; p=0.273$ and 0.087 , respectively). Hypertension and left ventricular ejection fraction (LVEF) that were significant $(\mathrm{OR}=1.51$ and $1.53 ; 95 \% \mathrm{Cl}=1.05-2.10$ and $1.32-1.78 ; p=0.026$ and 0.049 , respectively) in univariate analysis were found to be insignificant (OR $=1.36$ and $1.15 ; 95 \% \mathrm{Cl}=0.92-1.95$ and $0.98-1.35$; $p=0.114$ and 0.087 , respectively) in multivariate regression analysis. Diabetes mellitus and dyslipidemia were found to be the independent predictors for developing adverse in-hospital outcome after $\mathrm{PCls}(\mathrm{OR}=1.68$ and $1.46 ; 95 \% \mathrm{Cl}=1.25-2.24$ and $1.16-1.83 ; p=0.018$ and 0.040 , respectively). BMI was inversely associated with adverse in-hospital outcome after adjustment by multivariate logistic regression analysis $(\mathrm{OR}=0.95 ; 95 \% \mathrm{Cl}=0.91-0.98$; $p=0.007$ ) (Table IX).

Table-V

Comparison of the study population by clinical presentations $(N=100)$

\begin{tabular}{|c|c|c|c|c|c|c|c|}
\hline \multirow[t]{3}{*}{ Diagnosis } & \multicolumn{4}{|c|}{$\mathrm{BMI}$} & \multicolumn{2}{|c|}{ Total $(N=100)$} & \multirow[t]{3}{*}{$p$-value } \\
\hline & \multicolumn{2}{|c|}{ Group I $(n=50)$} & \multicolumn{2}{|c|}{ Group II $(n=50)$} & & & \\
\hline & Number & $\%$ & Number & $\%$ & Number & $\%$ & \\
\hline CSA & 6 & 12.0 & 5 & 10.0 & 11 & 11.0 & $0.27^{\mathrm{NS}}$ \\
\hline UA & 6 & 12.0 & 7 & 14.0 & 13 & 13.0 & \\
\hline NSTEMI & 9 & 18.0 & 11 & 22.0 & 20 & 20.0 & \\
\hline STEMI & 29 & 58.0 & 27 & 54.0 & 56 & 56.0 & \\
\hline
\end{tabular}

Group I = Patients with BMI $<23 \mathrm{~kg} / \mathrm{m}^{2}$

Group II = Patients with $\mathrm{BMI} \geq 23 \mathrm{~kg} / \mathrm{m}^{2}$

CSA $=$ Chronic Stable Angina

$\mathrm{UA}=$ Unstable Angina

NSTEMI = Non-ST-segment Elevation Myocardial Infarction

STEMI = ST-segment Elevation Myocardial Infarction

NS $=$ Not Significant $(p>0.05)$

$p$-value reached from chi-squared $\left(\chi^{2}\right)$ test

Table-VI

Comparison of the study groups according to their $\operatorname{LVEF}(N=100)$

\begin{tabular}{|c|c|c|c|c|c|c|c|}
\hline \multirow[t]{3}{*}{ LVEF } & \multicolumn{4}{|c|}{$\mathrm{BMI}$} & \multicolumn{2}{|c|}{ Total $(\mathrm{N}=100)$} & \multirow[t]{3}{*}{$p$-value } \\
\hline & \multicolumn{2}{|c|}{ Group I $(n=50)$} & \multicolumn{2}{|c|}{ Group II $(n=50)$} & \multirow[b]{2}{*}{ Number } & \multirow[b]{2}{*}{$\%$} & \\
\hline & Number & $\%$ & Number & $\%$ & & & \\
\hline$<50$ & 23 & 46.0 & 29 & 58.0 & 52 & 52.0 & $\mathrm{a} 0.79^{N S}$ \\
\hline$>50$ & 27 & 54.0 & 31 & 62.0 & 58 & 58.0 & \\
\hline Mean \pm SD & \multicolumn{2}{|c|}{$53.4 \pm 8.2$} & \multicolumn{2}{|c|}{$52.1 \pm 8.1$} & \multicolumn{2}{|c|}{$53.3 \pm 8.1$} & ${ }^{b} 0.69^{N S}$ \\
\hline
\end{tabular}

Group I = Patients with BMI $<23 \mathrm{~kg} / \mathrm{m}^{2}$

Group II = Patients with $\mathrm{BMI} \geq 23 \mathrm{~kg} / \mathrm{m}^{2}$

LVEF = Left Ventricular Ejection Fraction

NS $=$ Not Significant $(p>0.05)$

${ }^{a} p$-value reached from chi-squared $\left(\chi^{2}\right)$ test

${ }^{\mathrm{b}} p$-value reached from unpaired t-test 
Table-VII

Comparison of the study groups by length of hospital stay after PCI $(N=100)$

\begin{tabular}{|c|c|c|c|c|c|c|c|}
\hline \multirow[t]{3}{*}{ Length of stay } & \multicolumn{4}{|c|}{ BMI } & \multirow{2}{*}{\multicolumn{2}{|c|}{ Total $(\mathrm{N}=100)$}} & \multirow[t]{3}{*}{$p$-value } \\
\hline & \multicolumn{2}{|c|}{ Group I $(n=50)$} & \multicolumn{2}{|c|}{ Group II $(n=50)$} & & & \\
\hline & Number & $\%$ & Number & $\%$ & Number & $\%$ & \\
\hline$<72$ hours & 27 & 54.0 & 36 & 72.0 & 63 & 63.0 & ${ }^{\mathrm{a} 0} 0.036^{\mathrm{s}}$ \\
\hline 72 - 96 hours & 11 & 22.0 & 12 & 24.0 & 23 & 23.0 & \\
\hline$>96$ hours & 12 & 24.0 & 2 & 4.0 & 14 & 14.0 & \\
\hline Mean \pm SD & \multicolumn{2}{|c|}{$70.9 \pm 34.3$} & \multicolumn{2}{|c|}{$56.0 \pm 16.7$} & \multicolumn{2}{|c|}{$59.3 \pm 22.5$} & ${ }^{b} 0.005^{s}$ \\
\hline
\end{tabular}

Group I = Patients with BMI $<23 \mathrm{~kg} / \mathrm{m}^{2}$

Group II = Patients with BMI $\geq 23 \mathrm{~kg} / \mathrm{m}^{2}$

$\mathrm{S}=$ Significant $(p<0.05)$

${ }^{a} p$-value reached from chi-squared $\left(\chi^{2}\right)$ test and Fisher exact test

${ }^{\mathrm{b}} p$-value reached from unpaired t-test

Table-VIII

Comparison of the study groups by in-hospital outcomes after PCl $(N=100)$

\begin{tabular}{|c|c|c|c|c|c|c|c|}
\hline \multirow[t]{3}{*}{ Length of stay } & \multicolumn{4}{|c|}{$\mathrm{BMI}$} & \multicolumn{2}{|c|}{ Total $(\mathrm{N}=100)$} & \multirow[t]{3}{*}{$p$-value } \\
\hline & \multicolumn{2}{|c|}{ Group I $(n=50)$} & \multicolumn{2}{|c|}{ Group II $(n=50)$} & \multirow[b]{2}{*}{ Number } & \multirow[b]{2}{*}{$\%$} & \\
\hline & Number & $\%$ & Number & $\%$ & & & \\
\hline Adverse outcomes & 11 & 22.0 & 3 & 6.0 & 14 & 14.0 & $0.006^{S}$ \\
\hline Chest pain & 2 & 4.0 & 1 & 2.0 & 3 & 3.0 & $0.630^{\mathrm{NS}}$ \\
\hline Arrhythmia & 2 & 4.0 & 0 & 0.0 & 2 & 2.0 & $0.058^{N S}$ \\
\hline Access site complicat & ions 1 & 2.0 & 1 & 2.0 & 2 & 2.0 & $0.630^{\mathrm{NS}}$ \\
\hline Acute LVF & 4 & 8.0 & 0 & 0.0 & 4 & 4.0 & $0.007^{\mathrm{S}}$ \\
\hline Shock & 2 & 4.0 & 0 & 0.0 & 2 & 2.0 & $0.058^{N S}$ \\
\hline Death & 0 & 0.0 & 1 & 2.0 & 1 & 1.0 & $0.594^{\mathrm{NS}}$ \\
\hline
\end{tabular}

Group I = Patients with $\mathrm{BMI}<23 \mathrm{~kg} / \mathrm{m}^{2}$

Group II = Patients with BMI $\geq 23 \mathrm{~kg} / \mathrm{m}^{2}$

$\mathrm{S}=$ Significant $(p<0.05)$

NS $=$ Not Significant $(p>0.05)$

$p$-value reached from chi-squared $\left(\chi^{2}\right)$ test and Fisher exact test

Table-IX

Univariate and multivariate logistic regression analyses of variables associated with adverse in-hospital outcomes.

\begin{tabular}{|c|c|c|c|c|c|c|}
\hline \multirow{2}{*}{$\begin{array}{l}\text { Variables of } \\
\text { interest }\end{array}$} & \multicolumn{2}{|c|}{ Univariate analysis } & \multirow[t]{2}{*}{$p$-value } & \multicolumn{2}{|c|}{ Multivariate analysis } & \multirow[t]{2}{*}{$p$-value } \\
\hline & OR & $95 \% \mathrm{Cl}$ of $\mathrm{OR}$ & & OR & $95 \% \mathrm{Cl}$ of $\mathrm{OR}$ & \\
\hline Smoking & 1.29 & $0.82-1.78$ & 0.273 & & & \\
\hline Hypertension & 1.51 & $1.05-2.10$ & 0.026 & 1.36 & $0.92-1.95$ & 0.114 \\
\hline Diabetes & 1.97 & $1.61-2.41$ & 0.011 & 1.68 & $1.25-2.24$ & 0.018 \\
\hline Dyslipidemia & 1.54 & $1.11-1.72$ & 0.034 & 1.46 & $1.16-1.83$ & 0.040 \\
\hline Family history & 1.10 & $0.46-1.75$ & 0.087 & & & \\
\hline LVEF & 1.53 & $1.32-1.78$ & 0.049 & 1.15 & $0.98-1.35$ & 0.087 \\
\hline BMl & 0.89 & $0.87-0.92$ & 0.004 & 0.95 & $0.91-0.98$ & 0.007 \\
\hline
\end{tabular}

\section{Discussions:}

In the general population, obesity is associated with increased risk of adverse outcomes. However, studies of patients with chronic disease suggest that overweight and obese patients may paradoxically have better outcomes than lean patients. ${ }^{8}$ A number of studies have shown that the lean patients and those with normal BMI are at a higher risk for adverse in-hospital outcomes and post-PCl complications than overweight and obese patients. This is contrary to the common clinical 
perception that overweight and obese patients would be at a higher risk of adverse outcomes following $\mathrm{PCl}$. This unexpected phenomenon was explained by "obesity paradox". ${ }^{17}$ To date, there is not a complete understanding of this complex effect.

A number of studies have shown that lean patients $(<20$ $\left.\mathrm{kg} / \mathrm{m}^{2}\right)$ and those with normal BMI (20-24.9 $\left.\mathrm{kg} / \mathrm{m}^{2}\right)$ are at a higher risk for adverse in-hospital outcomes and post$\mathrm{PCl}$ complications than overweight $\left(25-29.9 \mathrm{~kg} / \mathrm{m}^{2}\right)$ and obese $\left(\geq 30 \mathrm{~kg} / \mathrm{m}^{2}\right)$ patients. ${ }^{17-19}$ In the current study, inhospital adverse outcomes after $\mathrm{PCl}$ was significantly higher in Group I also. Compared with normal-weight individuals, overweight and obese patients had shorter mean length of hospital stay (LOS) after PCl. Among all the adverse in-hospital outcomes, only LVF was found to be significantly more in Group-I. A study on 1,203 individuals with class IV heart failure found that higher $\mathrm{BMI}$ was associated with better survival, and multivariate analysis showed an inverse association between BMI and mortality. ${ }^{20} \mathrm{BMI}$ was inversely associated with post$\mathrm{PCl}$ adverse in-hospital outcome after adjustment by multivariate logistic regression analysis in this study. Gruberg et al. noticed that very lean patients (BMI <18.5) and those with normal BMI are at the highest risk for inhospital complications and cardiac death. ${ }^{17}$ Patients at the extremes of BMI $\left(<18.5\right.$ and $\left.>40 \mathrm{~kg} / \mathrm{m}^{2}\right)$ were also at increased risk of adverse outcomes after $\mathrm{PCl}^{21}$ Park et al. found that low BMI was associated with increased risks of adverse in-hospital outcomes and death. ${ }^{22}$ They also found no excess risks of these events to be associated with a high BMI. A Japanese real-world multicenter registry analysis reported that lean patients, rather than obese patients were at greater risk for inhospital complications during and after $\mathrm{PCl}^{22}$ Although obesity via its negative impact on systolic and diastolic function predisposes to overt heart failure, clinical evidence suggests that overweight/obese patients with heart failure paradoxically seem to have a better clinical prognosis than do their lean counterparts with clinical heart failure. An analysis based on 43,334 maintenance hemodialysis (MHD) patients, also showed an improved survival in those with higher BMI values. ${ }^{23}$

Finally, in a study by Lavie et al., a cohort of 529 patients in a cardiac rehabilitation program was evaluated. Survival analysis demonstrated that 20 patients with a BMI of more than 35 had the lowest mortality risk. ${ }^{24}$ This study further demonstrated that this relationship persisted with respect to body composition, whereby patients with the highest baseline percent body fat had a lower mortality risk when compared with patients with a normal baseline body fat $(2.8 \%$ vs $10.6 \%$, respectively). Fonarow and colleagues demonstrated a linear reduction in in-hospital mortality as the BMI increased. ${ }^{25}$ His findings showed a $10 \%$ reduction in mortality for every 5 -unit increase in BMI. ${ }^{5}$ Even, obesity was associated with better coronary flow after percutaneous coronary intervention and the number of lesions was lower in obese patients compared to non-obese elderly patients treated for STEMI. ${ }^{26}$

In essence, obesity is a risk factor for developing cardiovascular diseases, insulin-resistant diabetes, etc.; but after the onset of complications, obesity is a positive predictor for survival in various instances. The existence of this obesity paradox has led physicians to question whether obesity should be treated when associated with adverse clinical outcomes. ${ }^{20}$

\section{Conclusion:}

The underweight and normal weight people were at greater risk to experience in-hospital adverse outcomes than overweight and obese people following PCI. Though obesity is a recognized risk factor for cardiovascular diseases, once cardiovascular disease is developed, this obesity seems to play protective roles and provide some benefits. This 'Obesity Paradox' leads us to the necessity of reshuffling and reorganizing our plans whether we should take aggressive attempts or schemes to lose weight of an obese patient once he or she develops coronary artery disease.

\section{Limitations of the study}

There are some facts to be considered which might have affected the result of the current study.

- The study population was heterogeneous, including patients with different severities of CAD, ranging from chronic stable angina to myocardial infarction.

- The complexity of the lesions, procedural complications, use of anticoagulants and antiplatelets were not recorded which might have affected the incidence of complications in each of the BMI groups.

\section{Conflict of interest- None.}

\section{References}

1. Byers T. Body weight and mortality. New England Journal of Medicine. 1995;33311:723-724.

2. Manson JE, Willett WC, Stampfer MJ, Colditz GA, Hunter DJ, Hankinson SE, et al. Body weight and mortality among women. New England Journal of Medicine. 1995;33311:677-685.

3. Lew EA, Garfinkel L. Variations in mortality by weight among 750,000 men and women. Journal of Chronic Diseases. 1979;32:563-576.

4. Macdonald FC. Quetelet Index as Indicator of Obesity. The Lancet. 1986;3278488:1043.

5. Amundson DE, Djurkovic S, Matwiyoff GN. The obesity paradox. Critical care clinics. 2010;264:583-596. 
6. Kopple JD, Zhu X, Lew NL, Lowrie EG. Body weightfor-height relationships predict mortality in maintenance hemodialysis patients. Kidney international. 1999;563:1136-1148.

7. Kushner RF. Body weight and mortality. Nutrition reviews. 1993;515:127-136.

8. Curtis JP, Selter JG, Wang Y, Rathore SS, Jovin IS, Jadbabaie $F$, et al. The obesity paradox: body mass index and outcomes in patients with heart failure. Archives of internal medicine. 2005;165(1):55-61.

9. Kalantar-Zadeh K, Block G, Humphreys MH, Kopple JD. Reverse epidemiology of cardiovascular risk factors in maintenance dialysis patients. Kidney international. 2003;633:793-808.

10. Kalantar-Zadeh K, Block G, Horwich T, Fonarow GC. Reverse epidemiology of conventional cardiovascular risk factors in patients with chronic heart failure. Journal of the American College of Cardiology. 2004;438:1439-1444.

11. Islam AKMM, Majumder AAS. Coronary artery disease in Bangladesh: a review. Indian Heart Journal. 2013;654:424-435.

12. Siddiqui MKR, Karmakar PK, Nabi S, Hossain MA, Faroque SMO, Khuda CMKE, et al. Association of Body Mass Index with In-Hospital Left Ventricular Failure after Percutaneous Coronary Interventions. Bangladesh Heart Journal. 2018;33(1):39-46.

13. Siddiqui MKR, Azam SA, Karmakar PK, Nabi S, Karmaker P, Datta RK, et al. Impact of Body Mass Index on In-Hospital Outcomes after Percutaneous Coronary Interventions. Cardiovascular Journal. 2017;10(1):31-39.

14. Mann DL, Zipes DP, Libby P, Bonow RO, Braunwald $E$, editors. Braunwald's heart disease: A textbook of cardiovascular medicine. Philadelphia, PA: Elsevier/Saunders. 2015; volumes.

15. Gupta M, Brister S, Verma S. Is South Asian ethnicity an independent cardiovascular risk factor? Canadian Journal of Cardiology. 2006;22:193-197.

16. WHO Expert Consultation. Appropriate body-mass index for Asian populations and its implications for policy and intervention strategies. The Lancet. 2004;363:157-163.

17. Gruberg L, Weissman NJ, Waksman R, Fuchs S, Deible R, Pinnow EE, et al. The impact of obesity on the short-term andlong-term outcomes after percutaneous coronary intervention: the obesity paradox? Journal of the American College of Cardiology. 2002;39:578-584.

18. Ellis SG, Omoigui N, Bittl JA, Lincoff M, Wolfe MW, Howell G, et al. Analysis and comparison of operator-specific outcomes in interventional cardiology. From a multicenter database of 4860 quality-controlled procedures. Circulation. 1996;933:431-439.

19. Powell BD, Lennon RJ, Lerman A, Bell MR, Berger PB, Higano ST, et al. Association of body mass index with outcome after percutaneous coronary intervention. The American journal of cardiology. 2003;914:472-476.

20. Artham SM, Lavie CJ, Milani RV, Ventura HO. Obesity and hypertension, heart failure, and coronary heart disease-risk factor, paradox, and recommendations for weight loss. Ochsner Journal. 2009;93:124-132.

21. Minutello RM, Chou ET, Hong MK, Bergman G, Parikh $\mathrm{M}$, lacovone $\mathrm{F}$, et al. Impact of body mass index on in-hospital outcomes following percutaneous coronary intervention (report from the New York State Angioplasty Registry). The American journal of cardiology. 2004;9310:1229-1232.

22. Numasawa $Y$, Kohsaka S, Miyata H, Kawamura A, Noma S, Suzuki M, et al. Impact of body mass index on in-hospital complications in patients undergoing percutaneous coronary intervention in a Japanese real-world multicenter registry. PLOS ONE. 2015;104:e0124399.

23. Lowrie EG, Li Z, Ofsthun N, Lazarus JM. Body size, dialysis dose and death risk relationships among hemodialysis patients. Kidney international. 2002;625:1891-1897.

24. Lavie CJ, Ventura HO, Milani RV. The "obesity paradox": is smoking/lung disease the explanation? Chest. 2008;1345:896-898.

25. Gruberg L, Weissman NJ, Waksman R, Fuchs S, Deible R, Pinnow EE, et al. The impact of obesity on the short-term andlong-term outcomes after percutaneous coronary intervention: the obesity paradox? Journal of the American College of Cardiology. 2002;39:578-584.

26. Emre E, Ural E, Aktas M, Kahraman G, Bildirici U, Kilic T, et al. The Existence of Obesity Paradox and Effect of Obesity on In-Hospital-Outcomes on Elderly Patients Treated with Primary Percutaneous Coronary Intervention. International Journal of Gerontology. 2018;12:17-21. 